\title{
China English: To be or not to be? - A survey on the sociolinguistic background of its recognition and development
}

\author{
Jing Xie, Qiong Qu \\ College of Foreign Languages, China Three Gorges University, Yichang, China
}

Email address:

xiejing_ctgu@163.com (Jing Xie), 843450617@qq.com (Qiong Qu)

\section{To cite this article:}

Jing Xie, Qiong Qu. China English: To be or not to be? - A Survey on the Sociolinguistic Background of Its Recognition and Development. International Journal of Language and Linguistics. Vol. 2, No. 3, 2014, pp. 190-196. doi: 10.11648/j.ij11.20140203.18

\begin{abstract}
Spreading at the present rate, English will further increase its importance as the global lingua franca in this century, not only in countries of the inner and outer circles, but also in the expanding circle. Meanwhile, with the appearance of the 'craze for learning English' these past years in China, one of the EFL countries, more attention is focused on the research about this language phenomenon, and 'China English' thus has been proposed by Chinese linguists to represent the result of the localization and nativization of English in Chinese background. However, little notice about 'China English'has been taken by linguists and researchers in other countries. Also fewer empirical or survey studies can be found in this field since such research is only at the starting point in China. Therefore, this paper investigates the sociolinguistic background of the recognition and development of China English. 365 subjects of various levels are involved in the questionnaire survey. Their answers are about the ultimate aims of learning English and the social functions of English in their life. The results are in favor of a more objective and convincing conclusion, that is, China English is inevitably going to be an important variety of English and will exert the personal function of English for efficiency and effectiveness in both intercultural and intracultural communications. It is hoped that the discussion would help both recognition and acceptance of the new variety of English in the world. Suggestions on the relationship between China English and EFL teaching are also provided as references.
\end{abstract}

Keywords: China English, Sociolinguistic Background, Recognition, Development

\section{Introduction}

English is a language which has more non-native speakers than native speakers. And communication in English would happen not only between native speakers and non-native speakers but also among non-native speakers themselves, and usually in its localized varieties. Today, English is the most-studied foreign language in China. Kachru (1991:10 cited in Pan 2005: 36) argues that English in different socio-cultural contexts has multi-cultural identities and linguistic diversification. As Chin-Chuan Cheng (1992) says, 'The varieties of English spoken by native Chinese around the world presumably share certain features because of common language background' (Kachru 1992:162). The particular cultural 'meanings' and 'values', multiple semiotic systems, different linguistic conventions, and cultural traditions might be transplanted into this global language. The present study of China English is initiated by this belief. In 1982,
Ge Chuangui first brought the problem of China English and Chinese English into discussion in his paper on translation from Chinese into English. Research began to be done on the recognition and characteristics of China English since then, but less research has been done on the possibility and prospects of China English in terms of the sociolinguistic background. Therefore, this paper tries to explore the sociolinguistic background, such as functions of English and the ultimate aims of learning, to the recognition and acceptance of a local and global space for China English, in a country that is believed to have the largest number of foreign language learners.

This paper starts from the distinction of the two basic concepts: China English and Chinese English (also Chinglish), which are still in dispute among some linguists in this field. Some disagree with the existence of China English and think that it is simply a natural phenomenon in the process of language development and that it is not necessary and practical to create such a variety since there is the standard form of English. However, more support the 
proposal of China English and tries to provide more evidence to illustrate this issue in their own research (Wang 1991; Cheng 1992; Li 1993; Luo 1998; Du \& Jiang 2001; $\mathrm{Hu}$ 2002; Sun 2005). In this part, the distinction of the two concepts are summarized and the view I take is that China English, whose existence is already an objective fact, is an acceptable variety of English, while a certain amount of Chinese English is inevitable at a certain stage or stages of the English-learning process. It can be improved into standard and correct form of China English. It can be recognized as a continuum of language development.

It then goes to introduce the methodology including the subjects, instruments and procedures of the survey study and the data collected. From the questionnaire we can see the learners' or users' attitudes towards English, their ultimate aims of learning the language, and the functions of the language in their life, study and work. The results show that the majority of the subjects are far more likely to use English to communicate with Chinese people or other non-native speakers, and what they do or will do in English is all about 'Chinese-related' things. Even when they go abroad, their topics often cover those Chinese things or cultures. It is illustrated that the English they use in their life and work is not the so-called standard British or American English, but the variety of English with Chinese elements or expressions that may not exist in other varieties of English. And in the expanding circle where English is taught as a foreign language, in China for instance, English is used as an important tool to impart Chinese traditions and cultural values to the world.

In the later part, the issue of implications to English language teaching in college and university is discussed. It is hoped that the ultimate purposes of learning English and its social functions will help the teachers and educators to face the phenomenon in a more positive and optimistic way and make the practical and feasible decisions and reforms in foreign language teaching and learning policy.

\section{Distinction of the Two Concepts}

\subsection{China English and Chinese English (Also Chinglish)}

The question whether China English exists or not was believed to be brought into discussion by Ge Chuangui (1982). Since then, the name of China English was adopted by many others who joined the discussion (Sun 1989; Wang 1991; Li 1993; Xie 1995; Du \&Jiang 2001; Pan 2002, 2005; etc.). The main dispute in those articles is whether China English exists and what it is (Pan 2005:48). Many scholars provide definitions. Chinese English (or Chinglish) has been used to refer to the Pidgin English used by Chinese people to communicate with the foreigners in the past, especially in those port cities. According to $\operatorname{Li}(1993)$, it refers to the Sinicized English usually found in pronunciation, lexicology and syntax, due to the linguistic transfer or 'the arbitrary translation' by the Chinese English learners, thus being regarded as an unaccepted form of English. Deng and Liu
(2004:106) have pointed out that "Chinglish may be grammatically correct, but the choice of words or phrases and the manner of expression do not conform to Standard English usage. Although understanding may not be a problem, Chinglish is unacceptable." "While China English, mainly used as an international language in China, with Chinese borrowings, nativized lexicology as well as unique syntax and discourse structure as its major features, contributes much to the international communication"( $\mathrm{Li}$ 1993). Pan (2005: i) used another term CVE (Chinese Varieties of English), in its broad sense, to refer to English used by the speakers with Chinese linguistic and cultural background. CVE has the Chinese linguistic and cultural identities. It can reach the aim of communication and can be accepted by English speakers with other linguistic and cultural backgrounds.

\subsection{Dispute on the Existence of China English}

It is clear that the development of China English in the past years is originating from the globalization of English. However, for quite a long time, it has not been developed much since Ge proposed the concept of China English in 1982. In the first three years of the 21 st century, there has been a hot debate on the necessity to nativize English in China. Du \& Jiang $(2001 ; 2003)$ present an overview of "China English" studies in the past 20 years in their paper with much tentative analysis and believe that China English is an objective existence, while Qiu \& Ning (2002) "thinks it impractical and unnecessary to nativize English in China...for it is likely to affect and interfere with the popularization of Standard English...."

In this paper, I believe the definition of CVE given by Pan (2005), which is more acceptable and convincing to explain and illustrate the phenomenon of Chineseness of China English. Anyway, when English is spoken in Chinese linguistic and cultural background or related to Chinese things, the language is certainly to undergo a process of acculturation, which makes it inevitable to exclude particular Chinese terms and characteristics of the language and culture. The important point is that such usage is conforming to the Standard English usage and does not cause understanding problems in communication.

\subsection{Chinese English and China English---A continuum}

Though the distinction between China English and Chinglish is obvious, they two are interrelated in some aspects, not completely different things. According to Peter Strevens, Chinese English is the result of English learning of a certain stage, which is usually reflected by specific learners. When learners still haven' t master the language and meanwhile have to use it, their speech and writing is bound to be affected by their native language in communication. These expressions are regarded as typical Chinese English, which is not conform to the standard use of international English and is treated as wrong use of English. However, if enough time and efforts are devoted to 
English learning, learners may come to master the standard use of English and then Chinese English can be gradually developed into the acceptable variety: China English (Yan Zhiqiang 2002:227). In China there are more and more new English learners; that is to say, it is inevitable that the same number of learners will first become the users and creators of Chinese English. That explains why Chinese English are not dying though it is 'wrong' and unacceptable. The better way is to treat it as a normal stage in the continuum of English-learning process.

This study hopes to explore whether China English is going to exist and be accepted by the people in China or the outside world. And the following questions will be considered in order to answer this question: who is the actual users of English in China? What is their ultimate goal of learning the language? What social function English is playing in their life and study/work? And what is the current situation of China English?

\section{Methodology}

\subsection{Hypothesis on China English}

China English is inevitably going to be an important variety of English and would play a vital role in both intercultural and intracultural communication. The users will not be confined to Chinese people, but those whose work is related with Chinese people or their culture. And this discussion will certainly be of some help to the recognition and acceptance of the new variety of English in the world.

\subsection{Subjects}

There are altogether 365 subjects from different parts of China. The students' academic credentials range from low (S1) to high (S3), which indicate that S3's years of learning English are most probably longer than that of S2 and S1. The academic titles of Group $\mathrm{T}$ range from instructors to professors. Two of them are English teachers from XPU.

Table 1. Subjects.

\begin{tabular}{llll}
\hline 3 groups & 5 levels & Number & Percentage \\
\hline Employees & $\begin{array}{l}\text { Foreign trading Company in } \\
\text { Shenzhen(E) }\end{array}$ & 12 & $3.3 \%$ \\
& $\begin{array}{l}\text { Vocational students of Xi'an } \\
\text { Polytechnic University } \\
\text { Students }\end{array}$ & 137 & $37.5 \%$ \\
$\begin{array}{l}\text { (X) (S1) } \\
(85.2 \%)\end{array}$ & $\begin{array}{l}\text { Undergraduates of CTGU } \\
\text { (S2) }\end{array}$ & 156 & $42.7 \%$ \\
English & $\begin{array}{l}\text { Postgraduates in CTGU(S3) } \\
\text { teachers } \\
\text { TOTAL }\end{array}$ & 18 & $4.9 \%$ \\
\hline of CTGU\& XPU(T) & 42 & $11.5 \%$ \\
+3 groups; 5 levels; from 3 cities in the northwest, southeast and middle \\
parts of China
\end{tabular}

\subsection{Instruments}

Questionnaires. Two questionnaires are designed according to the groups of subjects: Questionnaire for
Students (Questionnaire I) and Questionnaire for College Teachers and Employees of Company (Questionnaire II). 20 items are included in each of them. The term "China English" is not mentioned directly in any of the items, so that the subjects' answers are not influenced or led by it.

Observations. Except for collecting data through questionnaire, long-term observations of Chinese learners', teachers' and workers' use of English and the characteristics observed in their use of the language are considered in this study. Besides, in order to obtain more first-hand data about the situation of China English, I also paid attention to teachers from some English-speaking countries who teach Chinese students English and talk to Chinese people in English in the Chinese background. It is shown that such "foreigner talk" or "teacher talk" is inevitable influenced by their Chinese students/subjects and the Chinese cultural background.

\subsection{Procedures}

i. 156 English majors (undergraduate students) in China Three Gorges University (CTGU) were selected from two large classes and two small classes. I asked their teachers to help me to hand out Questionnaire I during the interval of their classes and then collect them immediately after class. Also 18 questionnaires were answered by some postgraduates in CTGU whose research fields are English literature, linguistics or translation.

ii. To take geographic difference into consideration (i.e. to make the result more convincing and objective), I chose students of secondary vocational school in Xi'an Polytechnic University and asked a teacher there to help me finish the questionnaire-doing part during the break time of the class. Before doing the questionnaire, the teacher explained the directions to the students to make sure they understand well how to do it. Finally, 137 valid questionnaires were collected and posted from Xi'an of Shaan Xi province to me in $\mathrm{Hu}$ Bei province.

iii. Questionnaire II was delivered to two groups of subjects: 42 college teachers and 12 employees of a foreign trading company in Shenzhen (a developed city in the southeast part of China). I handed out 42 to some of my colleagues, ranging from instructors to professors, in Foreign Language College of CTGU before a regular Thursday meeting. And all of them were collected as valid ones. The other 12 questionnaires were delivered to some employees whose work was related to foreign trade, and collected through e-mails.

\section{Results and Discussion}

\subsection{Users of English}

The subjects in this study covers the major types of 
English learners in China, who represent the vast majority of English learners in this country. That is to say, English teachers, students of various levels, employees in foreign trading companies are the main groups of English learners and users in China. But do they use English as easily and smoothly as the natives? What topics do they prefer to talk about when speaking English? Is their English influenced by their L1? If yes, to what extent? Figure 1 provides evidence for this question. It is not out of expectation that $31 \%$ of the subjects' English are seriously influenced by their mother language, while $67 \%$ are more or less influenced. It also tells us that almost $98 \%$ of Chinese English learners and users are influenced by Chinese!

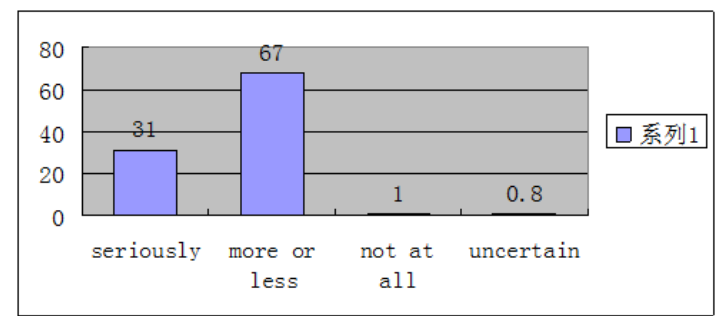

Figure 1. Influence of Chinese on the learners' English learning $(N=362)$

Figure 2 shows that $95 \%$ of the subjects hope to introduce Chinese culture and language to foreigners when they go abroad. The interesting thing is that the number of students who hope to introduce Chinese culture to foreigners are exactly the same in XPU and CTGU, which means the regional difference that may influence the attitude towards using China English are minimal and can be omitted.

Those who have studied or worked abroad admit that they often $(56 \%)$ or sometimes $(41 \%)$ mention topics and things about China to their foreign friends or partners which illustrates they are one group of the China English users.

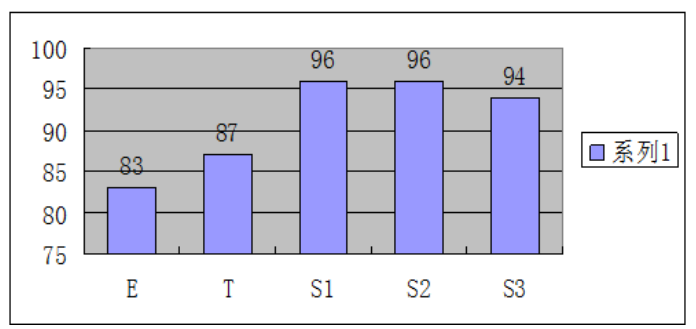

Figure 2. Percentage of of China English users among the five groups $(E=12 ; T=42 ; S 1=137 ; S 2=156 ; S 3=18)$

Except for Chinese users of China English, foreigners who work in China are another group of China English users. When they talk to their Chinese students, they often slow down their speed and explain difficult things by taking examples in Chinese language and culture. When talk with Chinese people during dinner, they are likely to talk about Chinese food and table manners. Then it is quite natural when they use words or expressions like "jiaozi", "baijiu", "ma po toufu" or things like that. When it comes to culture or ideologies, "laozi", "yinyang”, "xiucai”, etc. can be easily found in their speech and writing.

\subsection{Aims of Learning English}

We can predict without effort that the number of people who learn English in order to go abroad to study, work or travel is far less than those who want to improve themselves and use English to facilitate their life and career in China. The result of the survey proved this prediction. Only $32 \%$ of the subjects plan to go abroad in the future, among which the teachers accounts for $60 \%$ in the total number of 42 . It shows that most of the English learners are using/will use English within China---speaking English with Chinese people (89\%) or foreigners in China.

Their motivations and aims of learning English differ from person to person, for instance, some subjects want to pass various examinations $(56 \%)$ or prepare for future oversea studies $9 \%$ ); others learn/use it to meet the demands of work $(89 \%)$ and self-improvement $(52 \%)$, or because of their own interest in the language (38\%). No matter what kind of aims they want to achieve in learning English, the majority of the subjects' ultimate aims are definitely not to go abroad to communicate with native-speaker about their culture and traditions. The most practical objectives is either to utilize English in their own life and work and help foreigners know more about Chinese language traditional culture, or to communicate with people in China and other parts of the world more efficiently and effectively, not merely use English to talk with people from the inner-circle countries $^{1}$.

\subsection{Social Functions of English}

As Cheng (1992:163) has pointed out, in spite of the number of people involved in learning English, there is no English-speaking Chinese communities; nor does English serves as an interlanguage among the nation's fifty-six ethnic groups. In this sense, the functions of English are much different in China than in Africa (see Bamgbose 1982) and in South Asia (see Kachru 1981).

"According to Kachru (1992), English as a second language can have four functions: instrumental, regulative, interpersonal and creative" (Pan 2005:182). But these four functions, especially the second one, are not fully realized in Chinese context since English in China belongs to the expanding circle and has not been well developed into a new variety of English as Indian English or Singapore English.

Instrumental function. English functions as instrument in China in education, media, in the field of foreign trade and tourism, as well as in the progression of translation and international communication. It can be seen from Figure 3 that most teachers (T) and Undergraduates (S3) take positive attitudes towards the usefulness of English in their future job, and Figure 4 shows 60 percent of them think English is/will be very useful to their job, and another 35 percent think it useful, so the total number of subjects who take the positive attitude accounts for 95 percent, which shows the importance of English in their life. Among the 5 
levels of English learners/users, more than 80 percent of college English teachers and English-major postgraduates think English is very useful to their (future) job.

According to the survey and interview, their purposes of learning English are as follows: passing examinations; finding a better job, studying abroad and receiving higher education, improving one's own ability, lead a better life, etc. The social need for English reinforces its status in playing the instrumental function.

Interpersonal function. Results show that among 365 subjects, $84 \%$ prefer to choose topics which are their common interest, $27 \%$ prefer to talk about typical Chinese

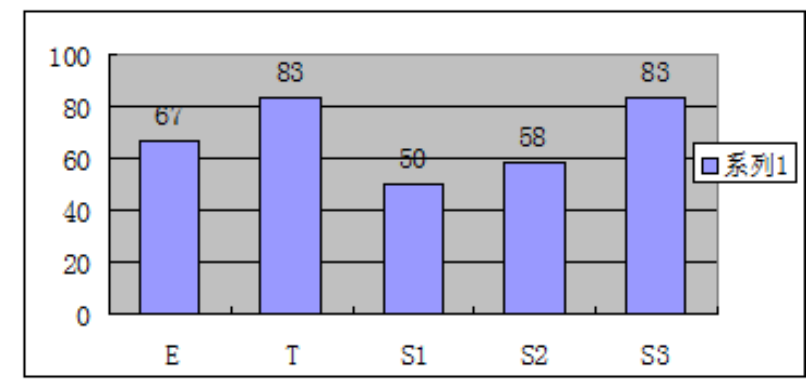

Figure 3. Numbers (in percentage) of different groups of subjects who take positive attitude towards the usefulness of English in their future job ( $E=12 ; T=42 ; S 1=137 ; S 2=156 ; S 3=18$, TOTAL $N=365$ )

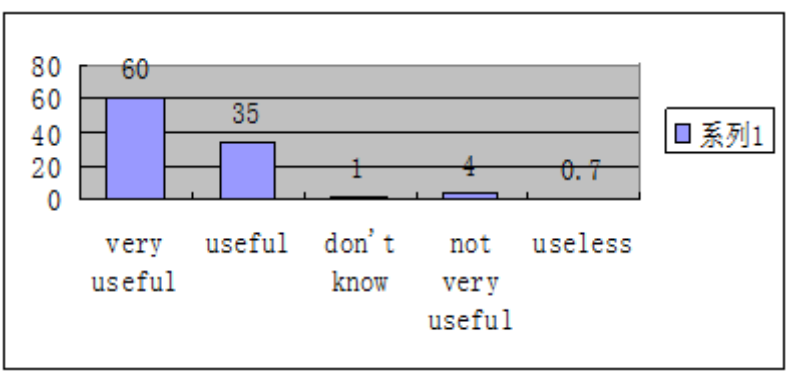

Figure 4. Degrees of the Usefulness of English to their (future) job

things in English, only $14 \%$ of them tend to involve themselves in conversations about things in English-speaking countries. These subjects are from all parts of China. They are students, teachers and employees, whose experiences of learning English range from 7 to 25 years. Although they are only a small number of the large population of English learners in China, their use of English can reflect how English performs its function in Chinese context since they are the representatives reflecting how English is used in China.

Creative function. When Chinese use English to communicate with people from other countries or produce non-native English literature for Western readers, English plays the international function and less Chinese elements would be included compared with the former function. For example, Lin Yutang's Moments in Peking (1941) is a marvelous novel suiting Chinese history and stories into English language, which were warmly welcomed and highly appreciated by Western readers and provide a window for them to know and understand Chinese people and their culture.

\subsection{Current Situation and Prospects of China English}

From the above discussion we can see clearly the existence of China English in real life and the necessity of its recognition as a non-native variety in the family of world English. However, the results are not all that optimistic and encouraging since problems still exist and much reforms and modification need to be done on the educational policy of English in China.

\subsubsection{Problems faced by Chinese English learners}

The controversial issue reflected in the investigation is that the learners are/were taught the language and culture of English-speaking countries (86\%) in the school, but use the language to communicate mostly with non-native English speakers, especially their countrymen in the Chinese background $(85 \%)$. Then problems arise inevitably when what they use is not so relevant to what they have learned in school. According to the result of the questionnaires, $82 \%$ subject meet obstacles/barriers when they talk in English with foreigners, in which $22 \%$ find the obstacles have caused big problems in intercultural communication. Only 2\% say they are free from any obstacles in their use of English. This number is apparently too small in terms of the total number of Chinese learners of English. That explains why only 4 teachers, among the total number of 365 , who have a lot of experiences of studying or working abroad, find no difficulties in talking about typical "Chinese things" such as social life, culture and education, etc. with foreign friends or colleagues. The rest admit that the difficulties lie mainly in several aspects, for instance, plenty of equivalent vocabulary and expressions are absent in English; their English courses are almost all about history and cultures of English-speaking countries while English courses on Chinese culture, traditions and history are rarely provided by the school; they are/were untaught of the ways to express and say things in English about Chinese culture and its traditions, to name just a few. Then the following problems are what we have to consider seriously:

Do we really have to teach our students standard American or British English and their cultures in school?

Is it necessary to merely indulge ourselves in those foreign cultures when we learn English simply as an instrument to facilitate our effectiveness and efficiency in communication not only with native-speakers, but also with people from non-native countries?

Can we do something to help our learners talk about "Chinese things" with foreigners more easily and smoothly?

$\mathrm{Hu}$ (2003) suggests that universities should offer some courses on Chinese society, history and literature in addition to all those courses on British and American history and literature for English-major students. It is shown in my present study (Table 2) that the number of the employees, teachers and students of different levels who think it (very) necessary for educational institutions to offer such courses accounts for $81 \%$, which is of great significance for English teaching in Chinese educational field. That means non-English majors also feel the necessity and importance of 
knowing how to express views and opinions in English about things happening in our daily life and work.

Table 2. Attitudes towards the necessity to offer English courses on Chinese history and culture.

\begin{tabular}{cccccc}
\hline & \multicolumn{5}{c}{ Attitudes (\%) } \\
Subjects & $\mathbf{5}$ & $\mathbf{4}$ & $\mathbf{3}$ & $\mathbf{2}$ & $\mathbf{1}$ \\
\hline $\mathrm{E}(\mathrm{N}=12)$ & 17 & 50 & 25 & 8 & 0 \\
$\mathrm{~T}(\mathrm{~N}=42)$ & 43 & 43 & 5 & 10 & 0 \\
$\mathrm{~S} 1(\mathrm{~N}=137)$ & 35 & 55 & 7 & 1.5 & 1.5 \\
$\mathrm{~S} 2(\mathrm{~N}=156)$ & 38 & 34 & 10 & 5 & 0 \\
$\mathrm{~S} 3(\mathrm{~N}=18)$ & 44 & 50 & 0 & 6 & 0 \\
Total & 37 & 44 & 8 & 4 & 0.5 \\
\hline
\end{tabular}

*Total $(\mathrm{N}=365)$

$5=$ very necessary

$4=$ necessary

$3=$ Don't care

$2=$ Not very necessary

$1=$ absolutely unnecessary

Hence, it may sound more reasonable and feasible if elective courses on "Chinese topics" can be offered to learners of different majors and levels in at least the higher educational institutions according to their future needs. Meanwhile, the quality of our English teachers and the method of instruction in schools need to be improved to ensure that students master basic language skills at an early stage of their education so that they can master real China English which can make their future intercultural communication more smoothly and efficiently instead of becoming the cause of misunderstandings.

\section{Conclusion}

There has never been a language so widely spread or spoken by so many people as English. New varieties of English emerged in the different territories where the language has taken root because they give identity to the groups which own them. International varieties thus express national identities (Crystal 1997/2001). That is, Chinese varieties of English express Chinese identities of the people. And the number of speakers involved in this new variety is huge and needs to be appreciated because China is the most populous country in the world and English is taught as a compulsory course from primary school (even kindergarten in some regions) to college. Therefore, China English is inevitably going to be an important variety in the family of 'World Englishes' and would exert the social functions of English for efficiency and effectiveness in both intercultural and intracultural communication. But there is still a long way to go to make China English recognized on the international scale and become a real variety or 'dialect' of the 'core English'. It is hoped that the discussion would help both recognition and acceptance of the new variety of English in the world. Educators and researchers need to face the phenomenon in a more positive and optimistic way, making practical and feasible decisions and undergo reforms in foreign language teaching and learning policies to facilitate the development of Chinese varieties of English and learners' mastery of it.

\section{Note}

(1) The US linguist Braj Kachru has suggested that we think of the spread of English around the world as three concentric circles: the inner circle, the outer/extended circle and the expanding circle, that is Kachru's Theory of Three Concentric Circles, representing different ways in which the language has been acquired and is currently used. (Crystal 1997/2001:53).

\section{References}

[1] Bamgbose, A. (1982). Standard Nigerian English. Issues of Identification. In Kachru (ed). The Other Tongue: English across Cultures. Pergamon Press. pp. 99 1 11 .

[2] Cheng, Chin-Chuan. "Chinese Varieties of English". In Kachru (ed.) (2nd edn.). The Other Tongue: English across Cultures. Oxford: Pergamon, 1992: 162-177.

[3] Crystal, David. English as a Global Language[M]. Cambridge University Press, 1997; Beijing: Foreign Language Teaching and Research Press, 2001.

[4] Deng, Yanchang and Runqing Liu. Language and Culture [M].Beijing: Foreign Language Teaching and Research Press, 2004.

[5] Du, Runqing and Yajun Jiang. China English0in the past 20 years[J]. Beijing: Foreign Language Teaching and Research Press, 2001(1).

[6] Ge, Chuangui. Talking about the Problems in Chinese to English Translation [J]. Translation Communication, 1980(2).

[7] Hu, Xiaoqiong. A Study of World Englishes and China English and Its Implications [J]. Journal of China Three Gorges University(Humanities \&Social Sciences ), 2003 (3).

[8] Jin, Huikang. Research on the Pragmatic Contexts and Functions of China English [J]. Fujian Foreign Language, 2001 (2).

[9] Kachru, Braj B. (ed.) The pragmatics of non-native varieties of English, In smith, ed. 1981.

[10] Kachru, Braj B. (ed.) The Other Tongue: English across Cultures [M]. Urbana and Chicago: University of Illinois Press, 1982/1992.

[11] Li, Wenzhong. China English and Chinglish [J]. Beijing: Foreign Language Teaching and Research Press, 1993(4).

[12] Pan, Zhangxian. Linguistic and Cultural Identities in Chinese Varieties of English [M]. Beijing: Peking University Press, 2005.

[13] Qiu, Lizhong and Quanxin Ning. Questioning on the Nativization of China English---Discussing with $\mathrm{Mr} \mathrm{Du}$ Runqing and Jiang Yajun [J]. Foreign Language Teaching, 2002(6).

[14] Wang, Rongpei. The Objective Existence of China English [J]. Journal of PLA University of Foreign Languages, 1991 (1). 
[15] Yasukata Yano. World Englishes in 2000 and Beyond [J]. World Englishes, 2001(2): 119-131.

[16] Yan, Zhiqiang. Introduction to World Englishes [M]. Beijing: Foreign Language Teaching and Research Press, 2002.
[17] Xie, Zhijun. China English: Interference Variety in Cross-culture Communication $[\mathrm{J}]$. Modern Foreign Language, 1995(4). 